\title{
OSACS score-a new simple tool for identifying high risk for Obstructive Sleep Apnea Syndrome based on clinical parameters
}

\author{
Filip M. Szymanski, Krzysztof J. Filipiak, Anna E. Platek, Anna Hrynkiewicz-Szymanska*, \\ Grzegorz Karpinski, Grzegorz Opolski
}

From Departments of Cardiology and *Cardiology-Hypertension and Internal Diseases, Medical University of Warsaw-Poland

\section{ABSTRACT}

Objective: Obstructive sleep apnea syndrome (OSAS) is a cardiovascular risk factor associated with clinical complications like hypertension, ischaemic heart disease or thrombosis. The aim of this study was to develop a new scoring system, based on objective clinical and echocardiographic parameters.

Methods: One hundred fifty-eight consecutive acute coronary syndrome (ACS) patients underwent standard clinical, laboratory and echocardiography assessment after ACS, and their risk of OSAS was assessed using Berlin Questionnaire and Epworth Sleepiness Scale. Creation of OSACS (Obstructive Sleep Apnea in Acute Coronary Syndrome patients) score was attempted, with risk factors evaluated in multiple logistic regression model.

Results: In 34.2\% patients, who were at high risk of OSAS left ventricular diastolic diameter, left atrial diameter, and intrventricular septal thickness were elevated. In multiple logistic regression analysis: history of hypertension (Odds Ratio $4.42 ; 95 \% \mathrm{Cl} 0.96-20.5, \mathrm{p}=0.06$ ), body mass index (OR 6.82; 95\% Cl 2.33-20; $\mathrm{p}<0.001$ ), diastolic blood pressure (OR 6.4; 95\% Cl 1.58-25.9; $\mathrm{p}=0.01$ ), left ventricular diastolic diameter (0R 3.5; 95\% $\mathrm{Cl}$ 1.05-11.6; $p=0.04$ ), left ventricular mass index (OR 0.26; 95\% Cl 0.07-0.94; $\mathrm{p}=0.04$ ), interventricular septal thickness (0R 4.44; $95 \% \mathrm{Cl} 1.15-17.1$; $\mathrm{p}=0.03$ ) were independent risk factors for high risk of OSAS. All independent risk factor were implemented into risk prediction model called OSACS. The area under the ROC curve for the OSACS score was 0.87 .

Conclusion: OSAS is highly prevalent in ACS patients. The new OSACS score has a high predictive value in assessment of risk of 0SAS in these patients, and it can be used as an objective tool, and an alternative for the Berlin Questionnaire. (Anatolian J Cardiol 2015; 15: 50-5)

Key words: acute coronary syndrome, obstructive sleep apnea syndrome, risk stratification

\section{Introduction}

Prevalence of sleep-disordered breathing in patients with cardiovascular disease is higher than in the general population (1-4). Obstructive sleep apnea (OSA) is the most common type of sleep apnea, associated with an increased risk of cardiovascular morbidity and mortality (5-8). In spite of its overwhelming importance, OSA remains largely underdiagnosed (9). Practitioners have two important tools for prescreening patient for risk of OSA, which can be further evaluated in polysomnography. First, of the two screening methods, is the Epworth Sleepiness Scale, which helps evaluate subjective daytime sleepiness. The Epworth Sleepiness Scale score ranges from 0 to 24, with values of 10 and higher considered indicative of an excessive daytime sleepiness (10). The second method-Berlin Questionnaire, is used to classify patients as at high or low risk of obstructive sleep apnea syndrome (OSAS) $(11,12)$. Unfortunately, both those methods base only on patients' self-reported status, and therefore cannot be objective. The aim of this prospective study was to develop a new scoring system, based on clinical and echocardiographic parameters, which will be useful in OSAS screening.

\section{Methods}

\section{Patient selection}

We prospectively studied 158 consecutive patients (mean age $57.1 \pm 8.7$ years, $68 \%$ male), admitted with acute chest pain of possible coronary etiology to a tertiary university hospital that provides 24-hour Cardiology Intensive Care Unit services. All study patients had first-ever myocardial infarction confirmed by an increase in serum cardiac troponin I concentrations (above $0.1 \mathrm{ng} / \mathrm{mL}$ ), and underwent primary percutaneous intervention. ST-segment elevation myocardial infarction was diagnosed when standard 12-lead ECG showed ST-segment elevation

Address for Correspondence: Dr. Filip M. Szymanski, Department of Cardiology, Medical University of Warsaw, 1 A Banacha Street, 02-097 Warsaw-Poland

Phone: +48 22 599-19-58 Fax: +48 22 599-19-57 E-mail: filip.szymanski@wum.edu.pl

Accepted Date: 01.11.2013 Available Online Date: 10.01.2014

(C) Copyright 2015 by Turkish Society of Cardiology - Available online at www.anakarder.com DOI:10.5152/akd.2014.5150 
found in two contiguous leads and be $\geq 0.25 \mathrm{mV}$ in men below the age of 40 years, $\geq 0.2 \mathrm{mV}$ in men over the age of 40 years, or $\geq 0.15$ $\mathrm{mV}$ in women in leads V2-V3 and/or $\geq 0.1 \mathrm{mV}$ in other leads (in the absence of left ventricular hypertrophy or left bundle branch block. Non ST-segment elevation myocardial infarction was diagnosed, when there was no persistent ST-segment elevation, and in the ECG there was ST-segment depression or T-wave inversion, flat $\mathrm{T}$ waves, pseudo-normalization of $\mathrm{T}$ waves, or no changes present (13).

\section{Study design}

The initial screening interview addressed patients' cardiovascular risk factors: age, history of hypertension, diabetes mellitus, dyslipidemia, risk of OSAS, daytime sleepiness, and other. Every study patient underwent transthoracic echocardiography (Philips iE 33, and 2,5-3,5 MHz transthoracic probe; Philips Medical System, USA) with assessment left ventricular diastolic diameter, left and right atrial diameter, posterior wall diastolic thickness, interventricular septal thickness, left ventricular mass, left ventricular mass index, and aortic diameter, left ventricular ejection fraction; coronary angiography, and biochemical screening including B-type Natriuretic Peptide (BNP), C-reactive protein concentration (CRP), and estimated glomerular filtration rate were performed. BNP was measured in whole-blood specimen with a fluorescence immunoassay Triage BNP Test ${ }^{\circledR}$ (Biosite ${ }^{\circledR}$ Incorporated, USA), and CRP with immunoturbidimetric method (Roche Diagnostics, GmbH, Mannheim, Germany). All patients were followed up for 30 days for major adverse cardiovascular events including myocardial infarction, symptom-driven revascularization, stroke, and all-cause mortality. Study protocol was approved by the Local Ethics Committee, and all participants provided written informed consent.

\section{Evaluation of high risk of OSAS}

A risk of OSA was assessed using the Berlin Questionnaire. Excessive daytime sleepiness was assessed with use of the Epworth Sleepiness Scale. The risk of OSAS was defined as high, based on positive Berlin Questionnaire and Epworth Sleepiness Scale score. Contents of the Berlin Questionnaire and Epworth Sleepiness Scale were previously described in detail $(10,11)$.

In the next part of the study, patients who were identified as at high risk of OSAS underwent, after a period of recovery from the myocardial infarction, an overnight sleep study, using a portable device, for diagnosing the sleep disorders (Embletta X30; Flaga, Reykjavik, Iceland) to confirm OSA, was performed. Apnea was defined as a cessation in airflow lasting $\geq 10$ seconds. Hypopnea was defined as a recognizable transient reduction (but not complete cessation) of breathing for 10 seconds or longer, a decrease of greater than $50 \%$ in the amplitude of a validated measure of breathing, or a reduction in amplitude of less than $50 \%$ associated with oxygen desaturation of $4 \%$ or more. The Apnea-Hypopnea Index (AHI) was calculated as a sum of apneas and hypopneas number per hour of sleep. OSA was diagnosed, when AHI reached over 5 per hour. The data were scored manually according to the recommendations of the American Academy of Sleep Medicine (14).

\section{Statistical analysis}

All analyses were performed using SAS statistical software version 8.02 (SAS Institute, Inc, Cary, NC). Continuous data are presented as mean \pm standard deviation and were compared using the Mann-Whitney $\mathrm{U}$ test or Student t-test. Categorical variables were compared using either $\chi^{2}$ or Fisher exact tests. A p value of less than 0.05 was considered statistically significant, whereas the confidence intervals were $95 \%$. Stepwise multiple logistic regression analysis was performed to identify the independent risk factors of "high risk of OSA". The covariates included into logistic regression analysis were: BNP level of $>100 \mathrm{pg} / \mathrm{mL}$, history of hypertension, history of diabetes, BMI of $>30 \mathrm{~kg} / \mathrm{m}^{2}$, diastolic blood pressure of $>90 \mathrm{~mm}$ $\mathrm{Hg}$ systolic blood pressure of $>140 \mathrm{~mm} \mathrm{Hg}$, highly sensitive CRP level >mean value for the study population, glomerular filtration ratio (GFR) >mean value for the study population, left ventricle diastolic diameter $>$ mean value for study population, interventricular septum $>$ mean value for study population, left atrium $>$ mean value for study population, right ventricle $>$ mean value for study population, posterior wall diastolic thickness $>$ mean value for study population, left ventricle ejection fraction >mean value for study population, left ventricle mass $>$ mean value for study population, and left ventricle mass index $>$ mean value for study population. The predictive value of the OSACS (Obstructive Sleep Apnea in Acute Coronary Syndrome patients) score was tested by the area under the receiver operator characteristic (ROC) curve.

\section{Results}

Fifty four (34.2\%) patients were at high risk, and 104 (65.8\%) at low risk of OSAS. In the group at high risk of OSAS there were $32(59.3 \%)$ patients with ST elevated myocardial infarction (STEMI), and $22(40.7 \%)$ patients with non-ST elevated myocardial infarction (NSTEMI). In patients at low risk of OSAS there were $73(70.2 \%)$ patients with STEMI and 31 $(29.8 \%)$ patients with NSTEMI. On admission patients at high risk of OSAS had more often history of hypertension $(92.6 \%$ vs. $55.8 \% ; p<0.001)$, diabetes mellitus ( $37 \%$ vs. $15.4 \% ; p=0.005)$ compared to the patients at low risk. OSAS high risk patients had significantly higher mean resting heart rate, systolic blood pressure, diastolic blood pressure, body mass index, higher level of serum CRP and lower glomerular filtration rate than low-risk patients. The mean BNP level at discharge was significantly higher in OSAS high-risk patients $(83.4 \pm 153.2$ vs. $18.5 \pm 22.2 \mathrm{pg} / \mathrm{mL} ; \mathrm{p}=0.001)$. There was a significantly higher mortality rate in patients at high risk of OSAS $(7.4 \%$ vs. $1 \%$; $\mathrm{p}=0.03)$. The major adverse cardiovascular events rate was higher in high risk of OSAS group $(16.7 \%$ vs. $5.8 \%$; $p=0.05)$ than 
in low-risk group. Baseline characteristics of the study population are described in detail in the Table 1.

As for the angiography findings in patients at high risk of OSAS, the infarct related artery in $19(35.2 \%)$ cases was left anterior descending artery, in $19(35.2 \%)$ cases right coronary artery, left circumflex artery in $7(13.0 \%)$ cases, left marginal artery in $4(7.4 \%)$ cases, and $5(9.3 \%)$ patients had no changes in coronary arteries. After the coronary angioplasty grading in TIMI score was respectively, TIMI 2-4 (7.4\%) patients, and TIMI 3-49 (92.6\%) patients. In the group at low risk of OSAS, left anterior descending artery was an infarct related artery in $36(34.6 \%)$ cases, right coronary artery in $33(31.7 \%)$ cases, left circumflex artery in $18(17.3 \%)$ cases, left marginal artery in $14(13.5 \%)$ cases, and diagonal branch in $1(1.0 \%)$ case, and $2(1.9 \%)$ patients had no changes in coronary arteries. After the coronary angioplasty, the grading was respectively, TIMI 2-7 (6.7\%) patients, and TIMI 3-97 (93.3\%) patients.

\section{Echocardiographic data}

There were statistically significant differences in echocardiographic parameters between the groups. High-risk patients' left ventricular diastolic diameter $(52.2 \pm 7.3$ vs. $48.2 \pm 5.1 \mathrm{~mm}$; $\mathrm{p}=0.01)$, left atrial diameter $(41.3 \pm 5.4$ vs. $38 \pm 4.6 \mathrm{~mm} ; \mathrm{p}=0.001)$ and interventricular septal thickness $(12.6 \pm 2.4$ vs. $11.5 \pm 1.7 \mathrm{~mm}$; $\mathrm{p}=0.003)$ were increased compared to low-risk subjects. The left ventricular mass $(300.7 \pm 105.7$ vs. $237.5 \pm 59.6 \mathrm{~g} ; \mathrm{p}=0.0002)$, and left ventricular mass index $(140.3 \pm 47.4$ vs. $122.8 \pm 28.2 \mathrm{~g} / \mathrm{m} 2 ; p=0.02)$ were significantly higher in high-risk patients. There was no statistically significant difference in left ventricular ejection fraction $(49.88 \pm 8.73$ vs. $49.79 \pm 8.75 \% ; p=0.95)$, right ventricular diameter $(25.66 \pm 3.01$ vs. $24.97 \pm 3.12 \mathrm{~mm} ; \mathrm{p}=0.199)$, and aortic diameter ( $32.2 \pm 4.7$ vs. $31.1 \pm 3.7 \mathrm{~mm} ; \mathrm{p}=0.26)$ between low- and high-risk patients (Table 1).

\section{Sleep study}

Initial screening with Epworth Sleepiness Scale and Berlin Questionnaire identified fifty three patients, who underwent an overnight sleep study (one patient of the initial group of 54 at high risk of OSAS had died). In total, 48 patients $(90.6 \%)$ were diagnosed as having OSA with an $\mathrm{AHI}>5$. Patients were classified into 3 groups according to the results of the sleep study (Apnea-Hypopnea Index): a) mild OSA in $18(37.5 \%)$ patients, b) moderate OSA in $17(35.4 \%)$ patients, and c) severe OSA in 13 $(27.1 \%)$ patients.

\section{OSACS score}

Basing on the multiple logistic regression analysis, parameters being independent risk factors for high risk of OSAS were defined. History of hypertension, body mass index, diastolic blood pressure, left ventricular diastolic diameter, left ventricular mass index and intraventricular septal thickness were independent risk factors for high risk of OSAS (Table 2). Using those factor a new score called OSACS (Obstructive Sleep Apnea in Acute Coronary Syndrome patients) was proposed. Basing on the Odds
Table 1. Subject characteristics by the risk of obstructive sleep apnea

\begin{tabular}{|c|c|c|c|}
\hline & $\begin{array}{l}\text { Low-risk } \\
\text { patients }\end{array}$ & $\begin{array}{l}\text { High-risk } \\
\text { patients }\end{array}$ & $\boldsymbol{P}$ \\
\hline \multicolumn{4}{|l|}{ Characteristics ( $\%$ or mean $\pm S D$ ) } \\
\hline Number of patients & $104(65.8 \%)$ & $54(34.2 \%)$ & --- \\
\hline Age, years & $57.07 \pm 9.06$ & $57.21 \pm 8.07$ & 0.9 \\
\hline Male & $69(66.3 \%)$ & $38(70.4 \%)$ & 0.7 \\
\hline $\begin{array}{l}\text { High risk of obstructive sleep apnea } \\
\text { based on Berlin Questionnaire }\end{array}$ & $3(2.9 \%)$ & $54(100 \%)$ & $<0.001$ \\
\hline Epworth sleepiness scale & $5.83 \pm 3.33$ & $14.83 \pm 3.02$ & $<0.001$ \\
\hline Epworth sleepiness scale $>10$ & $8(7.7 \%)$ & $54(100 \%)$ & $<0.001$ \\
\hline History of hypertension - no (\%) & $58(55.8 \%)$ & $50(92.6 \%)$ & $<0.001$ \\
\hline History of diabetes mellitus - no (\%) & $16(15,4 \%)$ & $20(37 \%)$ & 0.005 \\
\hline History of dyslipidemia - no (\%) & $49(47.1 \%)$ & $22(40.7 \%)$ & 0.58 \\
\hline \multicolumn{4}{|l|}{$\begin{array}{l}\text { Characteristics on admission } \\
(\% \text { or mean } \pm \text { SD })\end{array}$} \\
\hline Low-density lipoprotein, mg/dL & $117.96 \pm 36.37$ & $107.57 \pm 36.25$ & 0.12 \\
\hline $\begin{array}{l}\text { High sensitivity C-reactive protein, } \\
\mathrm{mg} / \mathrm{L}\end{array}$ & $11.06 \pm 18.41$ & $24.32 \pm 36.47$ & 0.07 \\
\hline Cardiac troponin I, ng/mL & $25.33 \pm 46.13$ & $19.97 \pm 33.84$ & 0.55 \\
\hline $\begin{array}{l}\text { Glomerular filtration rate, } \\
\mathrm{mL} / \mathrm{min} / 1.73 \mathrm{~m}^{2}\end{array}$ & $87.52 \pm 22.16$ & $79.5 \pm 21.18$ & 0.05 \\
\hline B-type natriuretic peptide, $\mathrm{pg} / \mathrm{mL}$ & $18.47 \pm 22.17$ & $83.41 \pm 153.15$ & $<0.001$ \\
\hline Heart rate, beats/minute & $80.48 \pm 21.76$ & $83.35 \pm 13.74$ & 0.04 \\
\hline Systolic blood pressure, $\mathrm{mm} \mathrm{Hg}$ & $128.36 \pm 23.57$ & $149.91 \pm 34.2$ & $<0.001$ \\
\hline Diastolic blood pressure, $\mathrm{mm} \mathrm{Hg}$ & $76.18 \pm 12.06$ & $87.65 \pm 17.49$ & $<0.001$ \\
\hline Body mass index, $\mathrm{kg} / \mathrm{m}^{2}$ & $26.99 \pm 3.81$ & $32.3 \pm 4.63$ & $<0.001$ \\
\hline Hospitalization time, days & $8.7 \pm 4.04$ & $10.4 \pm 5.24$ & 0.016 \\
\hline \multicolumn{4}{|l|}{ Echocardiographic data } \\
\hline $\begin{array}{l}\text { Left ventricular diastolic diameter, } \\
\mathrm{mm}(\text { mean } \pm S D)\end{array}$ & $48.23 \pm 5.13$ & $52.22 \pm 7.29$ & 0.01 \\
\hline $\begin{array}{l}\text { Intraventricular septal thickness, } \\
\mathrm{mm} \text { (mean } \pm \text { SD) }\end{array}$ & $11.46 \pm 1.72$ & $12.57 \pm 2.4$ & 0.003 \\
\hline Left atrial diameter, mm (mean \pm SD) & $38 \pm 4.59$ & $41.34 \pm 5.35$ & $<0.001$ \\
\hline $\begin{array}{l}\text { Right ventricular diameter, } \mathrm{mm} \\
\text { (mean } \pm \text { SD) }\end{array}$ & $24.97 \pm 3.12$ & $25.66 \pm 3.01$ & 0.20 \\
\hline $\begin{array}{l}\text { Posterior wall diastolic thickness, } \\
\text { mm (mean } \pm \text { SD) }\end{array}$ & $10.8 \pm 1.37$ & $11.27 \pm 2.06$ & 0.24 \\
\hline Aortic thickness, mm (mean $\pm S D)$ & $31.1 \pm 3.7$ & $32.2 \pm 4.7$ & 0.26 \\
\hline $\begin{array}{l}\text { Left ventricular ejection fraction, } \% \\
\text { (mean } \pm \text { SD) }\end{array}$ & $49.79 \pm 8.75$ & $49.88 \pm 8.73$ & 0.95 \\
\hline Left ventricular mass, $g$ (mean $\pm S D)$ & $237.53 \pm 59.6$ & $300.65 \pm 105.7$ & $<0.001$ \\
\hline $\begin{array}{l}\text { Left ventricular mass index, } \mathrm{g} / \mathrm{m}^{2} \\
\text { (mean } \pm \mathrm{SD})\end{array}$ & $122.79 \pm 28.22$ & $140.26 \pm 47.35$ & 0.02 \\
\hline Left ventricular hypertrophy, no. \% & $64(68.8 \%)$ & $35(72.9 \%)$ & 0.76 \\
\hline \multicolumn{4}{|c|}{$\begin{array}{l}\text { Continuous data are presented as mean } \pm \text { standard deviation and were compared using the } \\
\text { Mann-Whitney U test or Student } t \text {-test. Categorical variables are presented as no }(\%) \text {, and } \\
\text { were compared using either } \chi^{2} \text { or Fisher exact tests. } \\
\text { SD - standard deviation }\end{array}$} \\
\hline
\end{tabular}


Ratio (OR) for high risk of OSAS for every parameter, they were given point values ranging from -2 to +4 . In example left ventricular mass index of $>122,6 \mathrm{~g} / \mathrm{m}^{2}$, with OR $0.26(95 \% \mathrm{Cl} 0.07-0.94)$ was scored -2 , and $\mathrm{BMI}>30 \mathrm{~kg} / \mathrm{m}^{2}$ (OR $6.82 ; 95 \% \mathrm{Cl} 2.33-20$ ) or diastolic blood pressure > $90 \mathrm{~mm} \mathrm{Hg}$ (OR 6.4; $95 \% \mathrm{Cl} 1.58-25.9$ ) were scored +4 points. Total score was ranging from -2 points to +16 points (Table 3). The area under the ROC curve for the OSACS score was 0.87 (Fig. 1). According to the score patients were classified into the 3 groups: A) from -2 to +3 points - low risk group; B) from 4 to 8 points - intermediate risk group, and C) $\geq 9$ points - high risk group.

\section{Discussion}

OSACS is a newly proposed clinical score aiming to assess the risk of OSAS in acute coronary syndrome (ACS) patients. The score bases on objective clinical parameters including hypertension, body mass index, diastolic blood pressure, left ventricular diastolic diameter, left ventricular mass index, intraventricular septal thickness, which all proved to be independent risk factors for high risk of OSAS.

Early risk stratification of ACS patients is important to identify high short- and long-term risk of death, and occurrence of cardiovascular events. It is also essential for selection of proper medical treatment. The risk should be evaluated considering different clinical characteristics, risk factors, echocardiographic changes, and laboratorial markers (15). OSAS is a newly identified clinical condition, which if not diagnosed and treated in time, may lead to an increased risk of acute or recurrent cardiovascular events. Commonly used scales to evaluate the risk of ACS patients do not include OSAS as a risk factor for cardiovascular diseases (16-19). The high risk of OSAS also significantly increases cardiovascular morbidity and mortality $(5,7,20)$. Although in a small group of patients, we observed similarly to previous studies that patients at high risk of OSAS have higher risk of death. Other studies have also shown that OSAS patients have an increased risk of nocturnal death and myocardial infarction $(21,22)$.

Screening methods for OSA are more widely applicable than standard full polysomnography, but will never replace it. Sleep

Table 2. Independent variables associated with high risk of obstructive sleep apnea on multiple logistic regression analysis

\begin{tabular}{|l|c|c|}
\hline & $\begin{array}{c}\text { Odds ratio [95\% } \\
\text { confidence interval] }\end{array}$ & $\boldsymbol{P}$ \\
\hline History of hypertension & $4.42(0.96-20.5)$ & 0.06 \\
\hline Body mass index $>30 \mathrm{~kg} / \mathrm{m}^{2}$ & $6.82(2.33-20)$ & $<0.001$ \\
\hline Diastolic blood pressure $>90 \mathrm{~mm} \mathrm{Hg}$ & $6.4(1.58-25.9)$ & 0.01 \\
\hline Left ventricular diastolic diameter $>49 \mathrm{~mm}$ & $3.5(1.05-11.6)$ & 0.04 \\
\hline Intraventricular septal thickness $>12 \mathrm{~mm}$ & $4.44(1.15-17.1)$ & 0.03 \\
\hline Left ventricular mass index $>122.6 \mathrm{~g} / \mathrm{m}^{2}$ & 0.26 (0.07-0.94) & 0.04 \\
\hline $\begin{array}{l}\text { Stepwise multiple logistic regression analysis was performed to identify the independent risk } \\
\text { factors of "high risk of OSA". See text for the full list of variables included in the analysis }\end{array}$ \\
\hline
\end{tabular}

questionnaires and scores enforced by portable devices promise to be very helpful in risk stratification, initial diagnosis making, and managing OSAS in cardiologist patients. In addition they are cost efficient, and easily accessible. Both, Epworth Sleepiness Scale and Berlin Questionnaire have several limitations including poor sensitivity specificity, and reproducibility $(23,24)$. The presented OSACS score is simple to administer, and is promising to have a high predictive value in accurate assessment of the high risk of OSAS in ACS patients. As showed in ROC curve compression, OSACS has high predictive value. Although, it wasn't validated in a larger cohort. OSACS risk score has a potential of being as well or even more predictive of high risk of OSA than scales previously used. OSACS score is objective, and not basing on patients' answers and ability of interpretation of physicians. According to the guidelines of European Society of Cardiology, echocardiography is recommended in every patient undergoing ACS (Class of recommendation: I; Level of evidence: C) $(13,25)$. Also data considering: history of hypertension, BMI, and blood pressure are routinely covered on admission. Epworth Sleepiness Scale and Berlin Questionnaire are tools, which require additional examination from a physician. Our score is basing on data already provided by standard examinations. Contrary to the Berlin Questionnaire and Epworth Sleepiness Scale, the OSACS score is based on clinical parameters. The final OSACS score is calculated as the sum of: history of hypertension, body mass index, diastolic blood pressure, left ventricular diastolic diameter, left ventricular mass index and interventricular septal thickness. Previous evidence suggests that the presence of metabolic syndrome being more significant than typical clinical OSAS features, that include snoring and excessive daytime sleepiness, and other (12). It can be also possible that OSA should be included as a component of metabolic syndrome. The score, once properly validated, is intended to identify patients with high profile for OSA and accordingly, to be referred to the Sleep Lab. As said previously, same as other scores, it will not replace the polysomnography, but may help improve its accessibility, and cost effectiveness.

As expected, a number of conventional risk factors, such as: hypertension, diabetes or $\mathrm{BMI}>30 \mathrm{~kg} / \mathrm{m}^{2}$ in patients at high risk of OSAS was higher than in those at low risk. We have also shown

Table 3. Obstructive Sleep Apnea in Acute Coronary Syndrome patients (OSACS) score-the score to predict "high risk of obstructive sleep apnea"

\begin{tabular}{|l|l|}
\hline Question & \\
\hline Left ventricular mass index $>122.6 \mathrm{~g} / \mathrm{m}^{2}$ & -2 points \\
\hline Left ventricular diastolic diameter $>49 \mathrm{~mm}$ & +2 points \\
\hline History of hypertension & +3 points \\
\hline Intraventricular septal thickness $>12 \mathrm{~mm}$ & +3 points \\
\hline Diastolic blood pressure $>90 \mathrm{~mm} \mathrm{Hg}$ & +4 points \\
\hline Body mass index $>30 \mathrm{~kg} / \mathrm{m}^{2}$ & +4 points \\
\hline Total Score & $\ldots \ldots .$. points \\
\hline
\end{tabular}




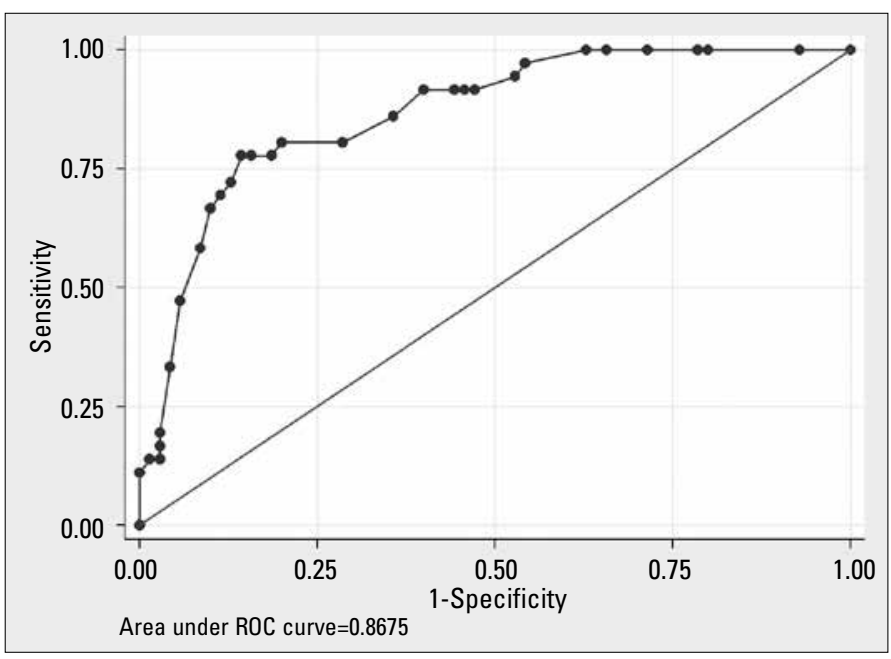

Figure 1. Predictive values of Obstructive Sleep Apnea in Acute Coronary Syndrome patients (OSACS) score-receiver operating characteristic (ROC) analysis

that high-risk OSAS patients have higher resting heart rate, compared to patients at low risk. Previous studies suggest that assessment of heart rate can improve the risk stratification (26). A higher heart rate is associated with an increased risk of cardiovascular, and other-cause mortality. In addition, our data confirmed previous results that high risk OSAS patients show elevated CRP level at admission, as compared to the low risk population.

It was previously shown that the measurements of BNP levels discharged ACS patients can be important in risk stratification of these patients. We observed that patients at high-risk of OSAS have higher mean BNP level at discharge. The elevated levels of BNP may be a precise indicator of cardiovascular morbidity and mortality in OSAS patients. Our OSAS high risk patients had longer hospitalization time as compared to low rsik group, which can strongly suggest a worse prognosis.

In our study population, the high risk of OSA was clearly associated with a significantly larger left ventricular diastolic diameter, larger left atrial diameter, thicker interventricular septum, significantly larger mass of the left ventricle and elevated left ventricular mass index. The observed enlarged left atrial diameter, left ventricular diameter, and thicker interventricular septum in patients at high risk of OSAS, this could be explained by a significant higher prevalence of arterial hypertension and obesity in those patients. The three echocardiographic parameters (left ventricular mass index $>122.6 \mathrm{~g} / \mathrm{m}^{2}$, left ventricular diastolic diameter $>49 \mathrm{~mm}$, and intraventricular septal thickness $>12 \mathrm{~mm}$ ) were independent risk factors for high risk for OSA. Echocardiographic parameters counted for most of the OSACS score points.

\section{Study limitations}

Several limitations must also be acknowledged. Present study is a preliminary study on proposal of the new clinical score that needs further validation. We did not perform an overnight sleep study in patients at low risk of OSAS. However, only $2.9 \%$ patients were at high risk of OSA basing on Berlin Questionnaire. The other limitation of the study is a relatively small number of patients involved which might impact on statistical power of the study. Finally, we did not make an external validation of this scale. On the other hand, we constructed non-invasive, simple and promising tool to identify those ACS patients who should be further diagnosed and treated more aggressively than only in context of post-myocardial risk. Cardiologists concentrated on ACS and post-ACS standards, should not forget about new risk factors like OSAS, and our risk score, even under validation by others', might increase the knowledge of OSAS.

\section{Conclusion}

OSAS is highly prevalent in ACS patients. In this group of patients, the new OSACS score has a high predictive value in assessment of the high risk of OSAS, and may be used as an alternative for the Berlin Questionnaire. Hypertension, body mass index, diastolic blood pressure, left ventricular diastolic diameter, left ventricular mass index, intraventricular septal thickness are all independent risk factors for high risk of OSAS. Further studies, including external validation, are needed to assess OSACS score accuracy in an everyday clinical practice.

\section{Conflict of interest: None declared.}

\section{Peer-review: Externally peer-reviewed.}

Authorship contributions: Concept - F.M.S., K.J.F., G.K.; Design - F.M.S., A.E.P.; Supervision - F.M.S., K.J.F; Resource F.M.S., K.J.F; Materials - F.M.S., A.E.P., G.K.; Data collection\&/or processing - A.E.P., A.H.S.; Analysis \&/or interpretation - F.M.S., K.J.F., G.K.; Literature search - A.E.P., F.M.S., G.K.; Writing - F.M.S., A.H.S., A.E.P., G.O.; Critical review - F.M.S., K.J.F., A.E.P., A.H.S., G.K., G.0.; Other - G.O.

Acknowledgments: This study was supported by grants from the Polish Cardiac Society, and has not received funding or grants from pharmaceutical or other industrial corporations.

\section{References}

1. Wolk R, Kara T, Somers VK. Sleep-disordered breathing and cardiovascular disease. Circulation 2003; 108: 9-12. [CrossRef]

2. Mooe T, Rabben T, Wiklund U, Franklin KA, Eriksson P. Sleep disordered breathing in men with coronary artery disease. Chest 1996; 109: 659-63. [CrossRef]

3. Schäfer H, Koehler U, Ewig S, Hasper E, Taşcı S, Lüderitz B. Obstructive sleep apnea as a risk marker in coronary artery disease. Cardiology 1999; 92: 79-84. [CrossRef]

4. Peker Y, Kraiczi H, Hedner J, Löth S, Johansson A, Bende M. An independent association between obstructive sleep apnoea and coronary artery disease. Eur Respir J 1999; 14: 179-84. [CrossRef]

5. Mooe T, Franklin KA, Holmstrom K, Rabben T, Wiklund U. Sleepdisordered breathing and coronary artery disease: long-term prognosis. Am J Respir Crit Care Med 2001; 164: 1910-3. [CrossRef] 
6. Saito T, Yoshikawa T, Sakamoto Y, Tanaka K, Inoue T, Ogawa R. Sleep apnea in patients with acute myocardial infarction. Crit Care Med 1991; 19: 938-41. [CrossRef]

7. Gottlieb DJ, Yenokyan G, Newman AB, O'Connor GT, Punjabi NM, Quan SF, et al. Prospective study of obstructive sleep apnea and incident coronary heart disease and heart failure: The Sleep Heart Health Study. Circulation 2010; 122: 352-60. [CrossRef]

8. Hrynkiewicz-Szymanska A, Szymanski FM, Filipiak KJ, Grabowski M, Dabrowska-Kugacka A, Karpinski G, et al. Can obstructive sleep apnea be a cause of in-stent thrombosis? Sleep Breath 2011; 15: 607-9. [CrossRef]

9. Young T, Peppard PE, Gottlieb DJ. Epidemiology of obstructive sleep apnea: a population health perspective. Am J Respir Crit Care Med 2002; 165: 1217-39. [CrossRef]

10. Johns MW. A new method for measuring daytime sleepiness: the Epworth sleepiness scale. Sleep 1991; 14: 540-59.

11. Netzer NC, Stoohs RA, Netzer CM, Clark K, Strohl KP. Using the Berlin Questionnaire to identify patients at risk for the sleep apnea syndrome. Ann Intern Med 1999; 131: 485-91. [CrossRef]

12. Drager LF, Genta PR, Pedrosa RP, Nerbass FB, Gonzaga CC, Krieger EM, et al. Characteristics and predictors of obstructive sleep apnea in patients with systemic hypertension. Am J Cardiol 2010; 105: 1135-9. [CrossRef]

13. Steg PG, James SK, Atar D, Badano LP, Blömstrom-Lundqvist C, Borger MA, et al. Task Force on the management of ST-segment elevation acute myocardial infarction of the European Society of Cardiology (ESC). ESC Guidelines for the management of acute myocardial infarction in patients presenting with ST-segment elevation: The Task Force on the management of ST-segment elevation acute myocardial infarction of the European Society of Cardiology (ESC). Eur Heart J 2012; 33: 2569-619. [CrossRef]

14. Epstein LJ, Kristo D, Strollo PJ Jr, Friedman N, Malhotra A, Patil SP, et al. Clinical guideline for the evaluation, management and longterm care of obstructive sleep apnea in adults. J Clin Sleep Med 2009; 5: 263-76.

15. Wijns W, Kolh P, Danchin N, Di Mario C, Falk V, Folliguet T, Garg S, et al. Task Force on Myocardial Revascularization of the European Society of Cardiology (ESC) and the European Association for Cardio-Thoracic Surgery (EACTS); European Association for Percutaneous Cardiovascular Interventions (EAPCI). Guidelines on myocardial revascularization. Eur Heart J 2010; 31: 2501-55. [CrossRef]

16. Yan AT, Yan RT, Tan M, Constance C, Lauzon C, Zaltzman J, et al. Canadian Acute Coronary Syndromes Registry Investigators. In-hospital revascularization and one-year outcome of acute coronary syndrome patients stratified by the GRACE risk score. Am J Cardiol 2005; 96: 913-6. [CrossRef]
17. Antman EM, Cohen M, Bernink PJ, McCabe CH, Horacek T, Papuchis G, et al. The TIMI risk score for unstable angina/non-ST elevation MI: a method for prognostication and therapeutic decision making. JAMA 2000; 284: 835-42. [CrossRef]

18. Morrow DA, Antman EM, Charlesworth A, Cairns R, Murphy SA, de Lemos JA, et al. TIMI risk score for ST-elevation myocardial infarction: A convenient, bedside, clinical score for risk assessment at presentation: An intravenous tPA for treatment of infarcting myocardium early II trial substudy. Circulation 2000; 102: 2031-7. [CrossRef]

19. Granger CB, Goldberg RJ, Dabbous O, Pieper KS, Eagle KA, Cannon $\mathrm{CP}$, et al. Global Registry of Acute Coronary Events Investigators. Predictors of hospital mortality in the global registry of acute coronary events. Arch Intern Med 2003; 163: 2345-53. [CrossRef]

20. Peker Y, Hedner J, Kraiczi H, Löth S. Respiratory disturbance index: an independent predictor of mortality in coronary artery disease. Am J Respir Crit Care Med 2000; 162: 81-6. [CrossRef]

21. Gami AS, Howard DE, Olson EJ, Somers VK. Day-night pattern of sudden death in obstructive sleep apnea. N Engl J Med 2005; 352: 1206-14. [CrossRef]

22. Kuniyoshi FH, Garcia-Touchard A, Gami AS, Romero-Corral A, van der Walt C, Pusalavidyasagar $S$, et al. Day-night variation of acute myocardial infarction in obstructive sleep apnea. J Am Coll Cardiol 2008; 52: 343-6. [CrossRef]

23. Geiger-Brown J, Rogers VE, Han K, Trinkoff A, Bausell RB, Scharf SM. Occupational screening for sleep disorders in 12-h shift nurses using the Berlin Questionnaire. Sleep Breath 2013; 17: 381-8. [CrossRef]

24. Nguyen AT, Baltzan MA, Small D, Wolkove N, Guillon S, Palayew M. Clinical reproducibility of the Epworth Sleepiness Scale. J Clin Sleep Med 2006; 2: 170-4.

25. Hamm CW, Bassand JP, Agewall S, Bax J, Boersma E, Bueno H, et al. ESC Guidelines for the management of acute coronary syndromes in patients presenting without persistent ST-segment elevation: The Task Force for the management of acute coronary syndromes (ACS) in patients presenting without persistent ST-segment elevation of the European Society of Cardiology (ESC). Eur Heart J 2011; 32: 2999-3054. [CrossRef]

26. Okin PM, Kjeldsen SE, Julius S, Hille DA, Dahlöf B, Edelman JM, et al. All-cause and cardiovascular mortality in relation to changing heart rateduringtreatmentofhypertensive patientswith electrocardiographic left ventricular hypertrophy. Eur Heart J 2010; 31: 2271-9. [CrossRef] 